\title{
Ética para a prática da comunicação responsável ${ }^{1}$
} Ethics for the practice of responsible communication

\section{Rosângela Gisoldi Orlandi}

Mestranda em Comunicação, pelo Programa de Mestrado da USCS - Universidade Municipal de São Caetano do Sul.

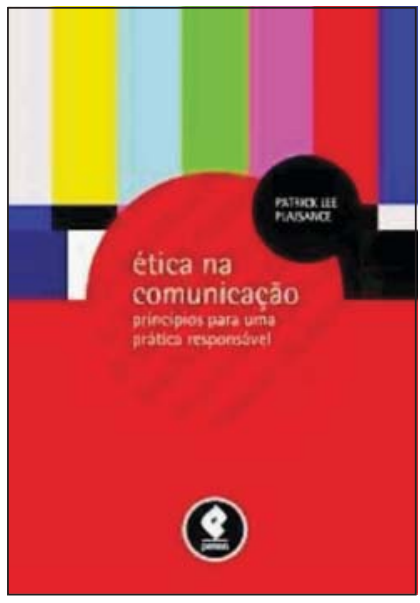

São crescentes os exemplos de comportamentos que colocam em dúvida a questão da ética nos meios de comunicação, vários deles protagonizados por organizações e outros tantos por profissionais que atuam na mídia ou dela se utilizam.

Ética na comunicação: princípios para uma prática responsável é uma obra que propõe a compreensão da base filosófica de princípios-chave que devem orientar o exercício de uma comunicação responsável. O autor, Patrick Lee Plaisance, é doutor em Comunicação de Massa, pela Syracuse University, e professor associado do Departamento de Jornalismo e Comunicação da Colorado University, onde leciona Ética da Comunicação, Reportagem e Teoria da Comunicação de Massa para turmas de graduação e pós-graduação.

Plaisance, que também escreveu o prefácio da sua própria obra, demonstrou várias vezes, ao longo de todo o texto, sua preocupação em abordar a essência das teorias que fundamentam a ética, de forma a propiciar a compreensão necessária para reflexões com maior conteúdo entre os estudiosos da área, no que diz respeito à sua aplicação na prática da comunicação responsável.

O livro compila o pensamento clássico e contemporâneo em relação a seis princípios: transparência, justiça, dano, autonomia, privacidade e comunidade, que vão ilustrar diversos estudos de caso apresentados pelo autor. São 295 páginas divididas em nove capítulos, sendo que os dois primeiros trazem a visão geral da ética e sua aplicação à comunicação. Do capítulo três ao oito, o autor dedicou cada um deles para tratar profundamente sobre os citados princípios.

O primeiro capítulo traz uma visão geral sobre a teoria da ética, compilando as ideias de pensadores clássicos e contemporâneos que se dedicaram ao estudo. De forma objetiva, a obra define os conceitos de ética e moral, que ainda hoje confundem aqueles que não se voltam à compreensão de suas características intrínsecas. Esclareceu o autor que, enquanto a moralidade refere-se a um modo geral e a um conjunto de crenças que são adotadas para ajudar o indivíduo a entender o que é bom e o que é mau no mundo em que vive, a ética trata da luta de cada um para justificar o fato de realizar ou não uma ação quando diversos valores do sistema pessoal de crenças entram em conflito (Plaisance, 2011: 25).

Pensadores como Aristóteles, Kant, Mill, Ross, Rawls e Benhabib foram abordados na essência do pensamento de cada um deles, construindo de forma prática as contribuições concorrentes neste tema.

No segundo capítulo, o autor discutiu a aplicação da ética no campo da comunicação e promoveu reflexões sobre a amplitude da missão dos profissionais e daqueles que se utilizam dos meios de comunicação. O livro está repleto de exemplos e de fatos reais por meio dos quais o autor procurou ilustrar os limites da profissão diante da ética e a eterna conquista e manutenção da credibilidade.

Plaisance destacou que, muitas vezes, embora haja a violação de valores e padrões profissionais, nem sempre a questão ética está em jogo. Grande parte dos casos classificados como "antiéticos" não passa de transgressões cometidas em atitudes sobre as quais não há o que refletir sobre qual seria a solução mais correta.

Na sequência, ele prosseguiu com a definição de cada um dos princípios trabalhados na obra e com a apresentação de exemplos que denominou como "casos representativos". Concluiu os capítulos oferecendo questões para discussão em sala de aula e propondo uma reflexão mais aprofundada sobre eles.

O capítulo três trata, com maior profundidade, do conceito de transparência, sendo que o autor destacou a importância deste princípio e o colocou como valor central no campo da ética. Com base no "princípio da humanidade" e na "teoria da dignidade humana" de Kant, Plaisance desenvolveu toda a fundamentação teórica sobre a transparência e expôs pensamentos de estudiosos contemporâneos que contrapõem ou complementam alguns aspectos abordados neste tema.

O autor finalizou o capítulo, trazendo à tona questões atuais em discussão na comunicação, em face da transformação de pessoas que passaram a adotar um perfil mais hostil diante de tantos casos jornalísticos, publicitários, de relações públicas ou, mesmo, no ciberespaço, quando servem para proteger interesses egoístas e, por isso, são julgados pela opinião pública como desprovidos de transparência. Para estas áreas da comunicação, a transparência é um elemento essencial da credibilidade.

O aumento do interesse pelos padrões de transparência e da aceitação destes está transformando o modo como as pessoas do setor dos meios 
de comunicação realizam seu trabalho (PlaISANCE, 2011: 89).

Plaisance iniciou o capítulo quatro sustentando que a justiça, o segundo princípio compilado pela obra, não é um assunto inerente aos tribunais e advogados, mas que "está ligada às nossas ideias gerais de equidade, que é um valor fundamental para boa parte do que percebemos como comunicação válida" (2011: 103). Ele destacou a justiça como um valor central nos meios jornalísticos. O capítulo traz elementos-chave essenciais do conceito de justiça, definidos por uma série de pensadores, e se volta para apresentar a teoria de John Rawls, passando, então, a discutir como essa teoria pode ser útil no enfrentamento de dilemas éticos da comunicação.

Com base em Rawls, Plaisance retratou a justiça como equidade nos meios de comunicação, alertando que, para os jornalistas, isso sugere uma necessidade de estar vigilante quanto à tentação de bajular pessoas famosas ou poderosas, tendo em vista a sua missão de dar voz a quem não tem, de sorte a servir, assim, a um público mais amplo. Para os profissionais de relações públicas, há uma obrigação ética na luta para a abertura de canais de comunicação aos menos favorecidos; já aos publicitários, traduz a justiça como o caminho para que se adotem campanhas socialmente responsáveis.

Para refletir sobre o dano, o autor trabalhou o capítulo cinco sob a ótica de vários filósofos e teóricos sociais com opiniões distintas, mas abordou especialmente os argumentos de John Stuart Mill e William D. Ross, que ele destacou como "notáveis". Defendeu que "a maior parte dos profissionais de comunicação está constantemente atenta à necessidade de minimizar o dano potencial, de evitar completamente causar dano às pessoas ou de pelo menos considerar com seriedade as reivindicações de dano." (Plaisance, 2011: 139). Em Ross, buscou compreender o que constitui a bondade e o dever de "não prejudicar os outros" e ressaltou em Mill o princípio do dano apresentado a partir do "princípio da liberdade", ainda que outros autores critiquem as suas limitações.

No conflito de valores que define todos os problemas éticos, é a ideia de "dano" potencial ou real e o nosso desejo de evitá-lo ou de minimizá-lo que entra em conflito com outros valores concorrentes como falar a verdade, utilidade pública e de prestação de contas (PlaisAnCE, 2011: 141).

Patrick Plaisance salientou, neste capítulo, que o conceito de "dano" é culturalmente determinado. A compreensão do dano e a atribuição de responsabilidade por ele se baseiam em normas políticas e sociais que são determinadas pela cultura.

\section{Ética para a prática da comunicação responsável}

O capítulo seis traz a autonomia como tema central para o aprofundamento das teorias que tratam deste princípio. Plaisance esclareceu que, embora a autonomia possa ser confundida com os conceitos de liberdade e independência, estes termos não devem ser utilizados como sinônimos dela. O capítulo em questão analisa o modo como os filósofos, tanto os clássicos como os contemporâneos, compreendem a autonomia e como ela está associada ao princípio da liberdade de expressão.

No contexto do processo comunicativo, o autor reforçou que "o respeito à autonomia é essencial em ambos os lados da equação da comunicação - tanto entre os envolvidos na produção das mensagens da comunicação como entre aqueles que recebem essas mensagens" (PLAISANCE, 2011: 174).

A privacidade, discutida no capítulo sete, é um dos princípios mais complicados quando se trata de comunicação nos dias de hoje, em razão da nova tecnologia de mídia que rompe barreiras, as quais tradicionalmente protegeram aquilo que se considerava privativo, conforme explanou o autor. Esse princípio, diferente dos que foram tratados nos capítulos anteriores, não orienta o comportamento humano, assim como o da "comunidade", que será objeto de reflexão no capítulo oito. Segundo Plaisance (2011: 207), a privacidade é algo externo à prática da comunicação, por isso não há expectativa de que seja incorporada por todos da forma como acontece com os outros princípios.

Como frutos de uma ideologia capitalista ocidental, os indivíduos são incentivados a praticar virtudes relacionadas a ações individuais e à autonomia, o que lhes permite "ser donos do [...] próprio destino". Com esta introdução, o autor sugeriu que o capítulo oito explore a base filosófica do conceito de comunidade e propôs que a compreensão dele deve embasar a tomada de decisão ética por parte de cada sujeito envolvido. Plaisance também destacou que tipo de papel o conceito de comunidade deve desempenhar na prática dos meios de comunicação. Para ele, a comunicação e a comunidade estão entrelaçadas, condição ratificada por Habermas, citado na obra (p. 262), e que atribui um papel decisivo à mídia na criação e na manutenção da esfera pública.

Ainda que diante de toda a complexidade que envolve a discussão sobre ética, aspecto que permeia diversas profissões, o autor demonstrou sua preocupação ao longo da obra em apresentar a raiz do conhecimento teórico sobre cada um dos princípios éticos para, na sequência, relacionar a compreensão e a aplicação dos princípios éticos no contexto da comunicação. Ele detalhou exemplos práticos que envolvem as áreas de relações públicas, jornalismo e publicidade, destinando em todos os capítulos um subtítulo específico para que o leitor possa acessar de forma rá- 


\section{Ética para a prática da comunicação responsável}

pida o direcionamento do tema às particularidades destas atividades.

Outra preocupação de Plaisance foi atualizar as teorias, ampliando a sua aplicação no ciberespaço, haja vista a evolução tecnológica que impõe questões éticas fundamentalmente novas, já que ela rompe barreiras como o tempo e o espaço, aumentando a dimensão do impacto que ações ou condutas duvidosas possam causar no meio social.

A obra, por fim, contribui para deixar claro que não há como ignorar ou minimizar a exigência da ética, ou pressupor que padrões éticos tão antigos não se apliquem à modernidade ainda que, diante dos avanços da tecnologia, nenhum canal de comunicação esteja dispensado dos padrões éticos básicos.

É evidente que a área da comunicação passa por momentos de vigilância sem precedentes por parte do público e de todos os segmentos interessados. Isso implica que os profissionais inseridos neste campo estejam devidamente preparados para desempenhar os seus devidos papéis diante da sociedade, o que torna o livro bastante apropriado para uso na formação de novos profissionais ou para a reciclagem dos que atuam em comunicação. 